\title{
Consanguineous Marriages in Finland and Their Implication for Genetic Disease
}

\author{
JAAKKO IGNATIUS
}

\author{
Medical Geneticist \\ Department of Medical Genetics \\ Väestöliitto, The Family Federation of Finland \\ Helsinki, Finland
}

\begin{abstract}
The frequency of marriages contracted between individuals with close consanguinity has traditionally been low in Finland. In the 19 th and early 20 th centuries only $0.1-0.3 \%$ of all marriages were contracted between first-cousins (average kinship coefficient 0.0001-0.0002). In genealogical search, however, a remote consanguinity (often beyond 3rd cousins) is frequently found especially in the rural areas and the true level of inbreeding is higher.

In Finland, several autosomal recessive diseases are known to be enriched in the population. This unique spectrum of genetic diseases is sometimes called »the Finnish Disease Heritage». To study the implication of close consanguinity for these disorders, information on consanguineous marriages closer than second-cousins was collected from 808 families representing 24 different »Finnish» autosomal recessive disorders. The mean rate of first-cousin marriages was $1.6 \%(0-20 \%)$. Consanguinity (parents second-cousins or closer) was found in $4.2 \%$ of the families. For comparison, in 160 families representing three "non-Finnish» autosomal disorders the corresponding figures were $1.9 \%$ and $2.5 \%$, respectively. Although these figures are high when compared to the general Finnish population, it can be concluded that close consanguinity is not a significant factor of Finnish genetic diseases.
\end{abstract}

Keywords: consanguineous marriage, consanguinity, autosomal recessive diseases, genetic diseases, Finland

\section{Introduction}

Consanguinity refers to the marriages contracted between genetically related individuals. As it is usually impossible to trace back very remote ancestors and thus prove (or exclude) the common genetic origin, in medical genetics consanguinity is usually defined as marriages between individuals who are second-cousins or more closely related (Cavalli-Sforza and Bodmer 1971; WHO 1985). The term »remote consanguinity» is often used if a genetic relation beyond second-cousins is found.

The frequency with which consanguineous matings occur in a given population depends on several factors. Consanguinity has been favored because of social and economic factors but sometimes it may also be practiced due to a lack of suitable mates outside of the family because of geographical, religious or cultural isolation. In the Western society consanguineous marriages are relatively rare. Instead, in many other 
parts of the world including Northern Africa and Southern and Western Asia, they are highly favored accounting for approximately $20 \%$ to $55 \%$ of all unions (Bittles 1990).

Avoiding consanguinity has often been attributed to its negative effects upon the genetic load of the population. Clearly, however, the attitudes more depend on the cultural and historical tradition of the society, and the religious and legal prohibitions on consaguineous marriages are not based on genetic risks alone. For example, in many countries - including Finland - marriages between half brother and half sister are prohibited and decreed incestuous, whereas marriages between double first-cousins, who are genetically identical to half sibling, are allowed. Marriages between very close relatives such as brother and sister or parent and child have traditionally been looked upon unfavorably in most societies.

Consanguineous marriages or inbreeding has long been a subject of interest to human geneticists because of the higher risk of autosomal recessive diseases as a result of consanguinity (Cavalli-Sforza and Bodmer 1971). An autosomal recessive trait is expressed only in homozygotes, which have received the recessive gene from both parents. The risk that a healthy carrier of a rare gene will mate another person carrying the same gene is higher if he or she mates a near relative.

To answer the question how closely the spouses are related and what is their share of common genes is answered by measuring the »inbreeding coefficient» (F). This indicates the proportion of autosomal loci predicted from pedigree analysis to be homozygous through inheritance of identical genes from common ancestors. If there is no mutation, inbreeding coefficient $\mathrm{F}$ is identical to the "coefficient of kinship» (f) of the parents. The offspring of first-cousin parents is likely to be homozygous at about $6 \%(F=1 / 16$ or 0.0625$)$ of gene loci, the figure for second-cousin parents being about $1.5 \%(\mathrm{~F}=1 / 64$ or 0.0156 ) (Cavalli-Sforza and Bodmer 1971). In most European populations the observed consanguinity rate is usually less than $1 \%$ and the values for $\mathrm{F}<0.001$ (Bittles 1990).

The convention to limit assessment of consanguinity to the second-cousin level appears reasonable because beyond this range, the coefficient of inbreeding of an individual increases only very slowly with the number of additional consanguineous marriages in his or her ancestry (Vogel and Motulsky 1986). In some isolated populations with uninterrupted endogamy over many centuries, however, the couples may become related through multiple pathways and the inbreeding coefficient may gradually reach very high values. Thus in a study on the Lancaster County Amish settlement in Northern America the mean inbreeding coefficient was 0.026 despite the conscious avoidance of close marriages in this society (McKusick 1978).

\section{Inbreeding in Finland}

There are only a few studies on inbreeding in Finland. Jorde and Pitkänen (1991) analyzed the frequency of first-cousin marriages using the royal dispensation records for the time period 1810-1872 and the national population statistics for 1878-1920. During the earlier period, $0.315 \%$ of Finland's marriages were contracted between firstcousins $(2,331$ of 739,387$)$ which yields an average kinship coefficient of 0.00020 . During the second time period (after the dispensation system had been abolished) the rate of first-cousin marriages was $0.174 \%(1,325$ of 761,976$)$ with an average kinship coefficient of 0.00011 , respectively.

Norio (1966) made an extensive genealogical study of the ancestry of 57 families with autosomal recessive congenital nephrosis. In this material, close consanguinity was rare and no first-cousin marriages were observed. Instead, several remote consanguinities between the parents were found. The inbreeding coefficient for the af- 
fected individuals was 0.00060 and for their parents 0.00170 , respectively. Nevanlinna (1972) studied the parish of Säkkijärvi in southeastern Finland and also by an extensive genealogy obtained an average inbreeding coefficient of 0.00867 for this study population. In the Sottunga parish, an island belonging to the Åland Archipelago, the average inbreeding coefficient was found to be 0.00210 , remote consanguinity again contributing more to inbreeding through time than close consanguinity ( $\mathrm{O}$ 'Brien et al. 1988).

\section{Purpose of the study}

For geneticists, Finland with her 5 million inhabitants offers an interesting and rare study object. It is an example of those populations that began as relatively small and marginal isolates and developed into a nation comprising several millions of people without much disturbance due to migration and admixture by other populations. As a result a unique collection of recessive diseases sometimes called the Finnish Disease Heritage has been found in Finland. This reflects how the random sample of recessive genes present by change in the founders is now represented in the current population (de la Chapelle 1993). The purpose of this study was to evaluate the implication of close consanguinity for these genetic disorders.

\section{Study material}

At present over 30 different disorders are considered to be typical for the Finns, 27 of them following autosomal recessive inheritance (de la Chapelle 1993). Many of them are very rare elsewhere. Published information about consanguineous marriages (first-cousins, first-cousins once removed, second-cousins) could be found in 24 of these disorders.

The diseases analyzed are (Table 1): Autoimmune polyendocrinopathy-candidosis-ectodermal dystrophy, APECED (Ahonen 1985); Aspartylglucosaminuria, AGU (Autio 1972); Congenital cloride diarrhoea, CCD (Norio et al. 1971a); Cartilage-hair hypoplasia, CHH (Mäkitie 1992); Congenital nephrosis, CNF (Norio 1966); Cohen syndrome (Norio, Raitta and Lindahl 1984, Tahvanainen et al. 1994); Cornea plana congenita (Eriksson et al. 1973); Diastrophic dysplasia, DD (Hästbacka et al. 1992); Gyrate atrophy of choroid and retina (Takki and Simell 1974); Infantile onset spinocerebellar ataxia with sensory neuropathy, IOSCA (Koskinen et al. 1994); Lethal congenital contracture syndrome, LCCS (Herva et al. 1985); Lysinuric protein intolerance, LPI (Norio et al. 1971b); Muscle-eye-brain disease, MEB (Santavuori et al. 1989); MULIBREY nanism (Lipsanen-Nyman 1986); Non-ketotic hyperglycinaemia, NKH (von Wendt, Hirvasniemi and Similä 1979); PEHO syndrome (Somer 1993, Somer 1995, personal communication); Progressive dementia with lipomembranous polycystic osteodysplasia, PLO-SL (Hakola 1990); Progressive myoclonus epilepsy, PME (Norio and Koskiniemi 1979); Salla disease, (Haataja 1994); Selective $B_{12}$ vitamin malabsorption, $\mathrm{SMB}_{12}$ (Furuhjelm and Nevanlinna 1973); Usher syndrome (Nuutila 1968), Gonadal dysgenesis, XX type, XXGD (Aittomäki 1994); Meckel syndrome (Salonen and Norio 1984) and Hydrolethalus syndrome (Salonen, Herva and Norio 1981). For the Meckel and Hydrolethalus syndromes, only data on first-cousin marriages were available.

To compare the findings with those obtained in autosomal recessive disorders which occur worldwide and thus are not considered to belong to the Finnish Disease Heritage, similar data were collected for three additional diseases and analyzed in a similar 
$\mathrm{T} \mathrm{a} \mathrm{b} 1$ e 1 . Consanguinity up to 2 nd cousins in 24 autosomal recessive disorders belonging to the Finnish Disease Heritage. $\mathrm{IC}=$ First cousins, IC o.r. $=$ First cousins once removed, $2 \mathrm{C}=$ Second cousins, n.a. $=$ Data not available. For Meckel syndrome and Hydroletalus only 1st cousin marriage data are available. For three additional »Finnish» disorders (INCL, Hereditary fructose intolerance and Congenital lactase deficiency) no consanguinity data has been published.

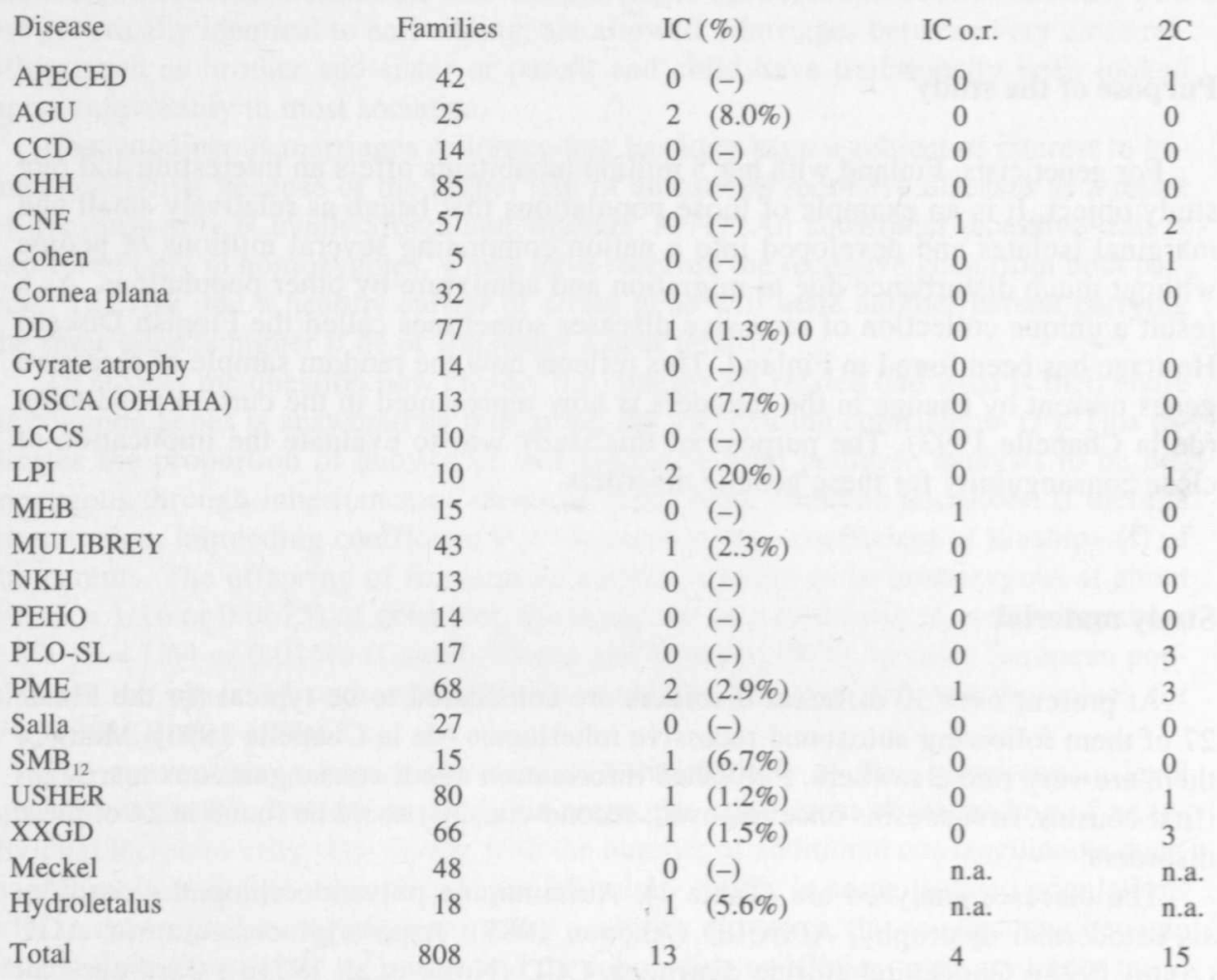

$\mathrm{T}$ a b 1 e 2. Consanguinity up to 2 nd cousins in three non-Finnish» autosomal recessive disorders.

\begin{tabular}{|c|c|c|c|c|}
\hline Disease & Families & & IC & IC o.r. \\
\hline $\mathrm{CF}$ & 20 & 0 & $(-)$ & n.a. \\
\hline SMA & 85 & 3 & $(3.5 \%)$ & - \\
\hline RPKD & 55 & 0 & $(-)$ & - \\
\hline Total & 160 & 3 & & 0 \\
\hline
\end{tabular}

way. These disorders are (Table 2): Cystic fibrosis, CF (Kere et al. 1989); Autosomal recessive polycystic kidney disease, ARPKD (Kääriäinen 1988) and Childhood onset spinal muscular atrophy, SMA (Ignatius 1992). 
To test the relevance of using the frequencies of first-cousin marriages in genetic studies dealing with the Finnish population, the Dahlberg formula (Emery 1986) was used to calculate the gene frequencies for two of these disorders. According to Dahlberg, if the frequency of first-cousin marriages in the general population (a) and among parents of affected children (C) are known then the gene frequency (q) can be estimated since

$$
q=\frac{a(1-C)}{16 C-C a-15 a}
$$

The gene frequencies obtained by using this formula were then compared with the previously reported gene frequencies for these disorders which have been calculated based on epidemiological data and the Hardy-Weinberg principle.

\section{Results}

The results are shown in Tables 1 and 2. In the whole material of 808 families no cases of parental consanguinity closer than first-cousins (uncle-niece, aunt-nephew) were reported. The mean rate of first-cousin marriages in the present material was $1.6 \%$. If compared to the figures by Jorde and Pitkänen (1991), this means a 10-fold increase in relation to the general population. However, there were considerable differences between different individual disorders. The highest rate of first-cousin marriages was observed in Lysinuric protein intolerance ( $20 \%$ of the marriages had been contracted between first-cousins). In four other disorders the rate of first-cousin marriages was > $5 \%$. On the other hand, in more than half (14/24) of the analyzed diseases no firstcousin marriages were found.

In addition, in four families the parents were found to be first-cousins once removed and in 13 families the parents were second-cousins. The mean rate of consanguinity (up to second-cousins) for the whole group was $4.2 \%$. Again, there were considerable differences between individual diseases: in seven disorders (29\%) consanguinities up to the second-cousin level were not found at all. Nearly 2/3 (19 out of 32 ) of the consanguineous marriages found occured in families representing five diseases (congenital nephrosis, lysinuric protein intolerance, progressive dementia with lipomembranous polycystic osteodysplasia, progressive myoclonus epilepsy and XXtype of gonadal dysgenesis). The highest rates of consanguinity were among the LPI and PLO-SL families (30\% and $17 \%$, respectively).

Among the 160 families with a non-Finnish recessive disease (cystic fibrosis, polykystic kidney disease or spinal muscular atrophy) only three first-cousin marriages were found and all these were in families with SMA. For SMA, the rate of firstcousin marriages was $3.5 \%$. The average rate of first-cousin marriages obtained for the non-Finnish disorders was $1.9 \%$. This figure is quite close to that $(1.6 \%)$ obtained in the study of the Finnish diseases. Consanguinities up to second-cousins were found in $2.5 \%$ of the families in this group of diseases.

There were 10 different Finnish diseases with first-cousin marriages reported among the parents. Two of these (AGU and DD) for which gene frequency estimations have be made using the Hardy-Weinberg principle were chosen to be analyzed using the Dahlberg formula.

Aspartylglucosaminuria (AGU) has a birth incidence of 1 in 18,500 live births in Finland (Arvio 1993) which corresponds to the gene frequency (q) of 0.007 . When using the Dahlberg formula and estimating the frequency of first-cousin mar- 
riages in the general population $(\mathrm{a})=0.0017$ a gene frequency of 0.00127 is obtained. This is a figure clearly lower than calculated based on the epidemiological data.

Diastrophic dysplasia (DD) has an estimated gene frequency of 0.008 in Finland (Hästbacka et al. 1992). By the method described above the estimated gene frequency is $(q)=0.009$ which is a figure only slightly higher than using the Hardy-Weinberg principle.

\section{Discussion}

In Finland, the rate of close consanguinity appears to be low. Obviously, there are no studies on the frequency of consanguineous marriages in present-day Finland. Some ethnic and often non-European minorities excluded, however, in other parts of Europe their number has rather been diminishing during this century and this most likely holds true even for Finland. Based on the data available, the rate of first-cousin marriages in Finland corresponds relatively well to the figures reported from other European populations (Bittles 1990).

Probably several historical religious as well as secular prejudices have contributed to the avoidance of this custom in Finland as well as in other parts of Europe. The Roman Catholic Church which had banned marriages up to and including third cousins already in AD 597 (Bittles 1994) regulated the marriage customs in the Medieval times. Even after the Protestant doctrine was introduced into Sweden and Finland, first-cousin marriages remained totally prohibited by law until 1680 . After this date, it was possible for the Lutherans to marry a first-cousin if a dispensation was obtained from the Crown. Because of religious proscriptions, however, first-cousin marriages did not occur among the Greek-Orthodox minority living in the Eastern Finland. After Finland had become part of Russia 1809, the requirement for dispensations was preserved until 1872 , when it was abolished.

In addition to the religious and juridical regulations also cultural tradition appears to have been against consanguineous marriages. Thus in parts of eastern Finland where family surnames have been consistently used for centuries, isonymous marriages (between individuals with the same surname) were looked upon unfavorably thus prohibiting marriages between the offspring of brothers and possibly even beyond first-cousin level (Lukkarinen 1933).

In the study by Jorde and Pitkänen (1991), somewhat unexpectedly, geographic distance between spouses' premarital residences, population density, parish endogamy or urban vs. rural residence were not found to be significant predictors of firstcousin marriages in general. Instead, husband's occupation and the »ethnic» composition of the parish as defined by the proportion of Swedish and Finnish speakers (the two official languages in Finland) were the best predictors of consanguinity for the whole of Finland. A notable exception was Lapland, the northernmost and very sparsely inhabited part of Finland which showed the highest kinship coefficients of 0.000674 and 0.000470 for the two time periods studied, respectively. The lowest values were found in the eastern provinces. The consanguinity rates were clearly higher among nobility, gentry and high-status land-owning farmers and they were also more likely to occur among the Swedish speaking part of the population (Jorde and Pitkänen 1991). Although these conclusions may be valid for the Finnish population as a whole, strong regional differences probably exist.

The rate of consanguineous marriages was above average in the group of families with children suffering from autosomal recessive diseases, as expected Interestingly, there seems to be no great differences between those diseases listed as a part of the Finnish Disease Heritage and those considered to be common all over the 
world. For most of the individual disorders studied here, no data from outside Finland are available for comparison; they are virtually non-existing elsewhere. Some reports on the rate of consanguinity in the non-Finnish disorders have been published and interestingly, the observed rate of first-cousin marriages among the Finnish SMA parents $(3.5 \%)$ is not very different from that reported from France where $4.5 \%$ of the parents of SMA children were found to be first-cousins (Tchen et al.1977). As the frequency of first-cousin marriages in the French population $(<0.2 \%)$ also corresponds well with the Finnish estimates, it can be concluded that at least in this autosomal recessive disease - consanguinity appears to play a very similar role both in France and in Finland as the cause of genetic disease.

In the present study very different consanguinity rates were observed in different disorders. Higher rates of consanguinity could be expected to occur associated with those diseases wich are very rare. The observed differences may, however, reflect the different geographical distributions of different disorders within the country and thus local customs rather than true differences in gene frequencies. It should be pointed out that some of the family materials used for analysis are relatively small when by chance too high consanguinity rates may have to be obtained. An example is aspartylglucosaminuria ( $\mathrm{AGU}$ ) which today is considered to be one of the most common Finnish diseases and today the number of AGU patients diagnosed exceeds 200 (de la Chapelle 1993). The study by Autio (1972) where a first-cousin marriage rate of $8 \%$ among the 25 families reported was found may well give an overestimation of the consaguinity rate in this disorder. This bias could also cause the very low gene frequency result obtained by using the Dahlberg formula. In diastrophic dysplasia with a larger family material the calculations using the Dahlberg formula apparently gives more reliable results.

Remote consanguinities between the parents have often been found in studies of Finnish diseases. Instead, there appears to be only few marriages with close consanguinities between the parents of children with autosomal rescessive diseases. Clearly, close consanguinity is not a significant cause of morbidity in Finland. Also the more remote consanguinities may reflect the lack of migration rather than be indicative to the ancestral line through which the disease causing mutation was passed further. In spite of the numerous remote consanguinities often found in genetic studies, as shown by Norio (1966) and Nevanlinna (1972), the inbreeding coefficients obtained in Finnish studies have not reached such high values as reported from e.g. the Amish and should not cause significant additional »genetic burden».

Recently, also the demographers have paid more attention to the role of consanguinity on reproductive behavior and prereproductive mortality on population level (Bittles 1994; Bittles and Neel 1994). Although with low rates of close consanguinity, Finland may be an interesting object for this type of studies.

\section{References}

Ahonen, P. 1985. Autoimmune polyendocrinopathy - candidosis - ectodermal dystrophy (APECED): autosomal recessive inheritance. Clinical Genetics 27:535-572.

Aittomäki, K. 1994. The Genetics of XX gonadal dysgenesis. American Journal of Human Genetics 54:844-851.

Arvio, M. 1993. Life with Aspartylglucosaminuria. Doctoral Dissertation. Helsinki: University of Helsinki

Autio, S. 1972. Aspartylglucosaminuria: analysis of thirty-four patients. Journal of Mental Deficiency Research Monograph Series 1.

Bittles, A.H. 1990. Consanguineous Marriage: Current Global Incidence and its Relevance to Demographic Research. Research Report 90-186. Ann Arbor, MI: Population Studies Center, University of Michigan. 
- 1994. The role and significance of consanguinity as a demographic variable. Population and Development Review 20(3):561-584.

Bittles, A.H. and J.V. Neel. 1994. The costs of human inbreeding and their implications for variations at the DNA level. Nature Genetics 8:117-121.

Cavalli-Sforza, L.L. and W.F. Bodmer. 1971. The Genetics of Human Populations. San Fransisco, CA: W.H. Freeman and Company.

de la Chapelle, A. 1993. Disease gene mapping in isolated human populations: the example of Finland. Journal of Medical Genetics 30:857-865.

Emery, A.E.H. 1986. Methodology in Medical Genetics. Edinburgh: Churchill Livingstone.

Eriksson, A.W., W. Lehmann, and H. Forsius. 1973. Congenital cornea plana in Finland. Clinical Genetics 4:301-310.

Furuhjelm, U. and H.R. Nevanlinna. 1973. Inheritance of selective malabsorption of vitamin B12. Scandinavian Journal of Haematology 11:27-34.

Haataja, L. 1994. The Gene Locus of Salla Disease. Annales Universitatis Turkuensis, Ser. D, 163. Doctoral dissertation. Turku: University of Turku.

Hakola, H. P. A. 1990. Polycystic Lipomembranous Osteodysplasia with Sclerosing Leucoencephalopathy (membranous lipodystrophy): a Neuropsychiatric Follow-Up Study. Monographs of Psychiatria Fennica 17. Helsinki: Foundation for Psychiatric Research in Finland.

Herva, R., J. Leisti, P. Kirkinen, U. Seppänen and J. Martikainen. 1985. Kuolemaan johtava synnynnäinen kontraktuuraoireyhtymä (A lethal congenital contracture syndrome). Duodecim 101:756-762.

Hästbacka, J., A. de la Chapelle, I. Kaitila, P. Sistonen, A.Weaver and E. Lander. 1992. Linkage disequilibrium mapping in isolated founder populations: diastrophic dysplasia in Finland. Nature Genetics 2:204-211.

Ignatius, J. 1992. Childhood Spinal Muscular Atrophy in Finland: A Clinical, Genetic and Nosological Study. Acta Universitatis Tamperensis, Ser. A 358. Doctoral dissertation. Tampere: University of Tampere.

Jorde, L.B., and K.J. Pitkänen. 1991. Inbreeding in Finland. American Journal of Physical Anthropology 84:127-139.

Kere, J., R. Norio, E. Savilahti, X. Estivill and A. de la Chapelle. 1989. Cystic fibrosis in Finland: a molecular and genealogical study. Human Genetics 83:20-25.

Koskinen, T., P. Santavuori, K. Sainio, M. Lappi, A-K Kallio and H. Pihko. 1994. Infantile onset spinocerebellar ataxia with sensory neuropathy: a new inherited disease. Journal of the Neurological Sciences 1994:121:50-56.

Kääriäinen, H. (1988): Polycystic Kidney Disease in Children. Doctoral Dissertation. Helsinki: University of Helsinki.

Lipsanen-Nyman, M. 1986. Mulibrey nanismi (Mulibrey nanism). Doctoral Dissertation. Helsinki: University of Helsinki.

Lukkarinen, J. 1933. Suomalaisten naimatapoja (Finnish marital customs). Helsinki: Suomalaisen Kirjallisuuden Seura.

McKusick, V. 1978. Medical Genetic Studies of the Amish. Baltimore, MD: The Johns Hopkins University Press.

Mäkitie, O. 1992. Cartilage-hair hypoplasia in Finland: epidemiological and genetic aspects of 107 patients. Journal of Medical Genetics 29:652-655.

Nevanlinna, H.R. 1972. The Finnish population structure: a genetic and genealogical study. Hereditas 71:195-236.

Norio, R. 1966. Heredity in the Congenital Nephrotic Syndrome: A Genetic Study of 57 Finnish Families with a Review of Reported Cases. Doctoral dissertation. Helsinki: University of Helsinki.

Norio, R., J. Perheentupa, K. Launiala, and N. Hallman. 1971a. Congenital cloride diarrhea, an autosomal recessive disease. Genetic study of 14 Finnish and 12 other families. Clinical Genetics 2:182192.

Norio, R., J. Perheentupa, M. Kekomäki and J.K. Visakorpi. 1971b. Lysinuric protein intolerance, an autosomal recessive disease: a genetic study of 10 Finnish families. Clinical Genetics 2:214-222.

Norio, R., and M. Koskiniemi. 1979. Progressive myoclonus epilepsy: genetic and nosological aspects with special reference to 107 Finnish patients. Clinical Genetics 15:382-398.

Norio, R., C. Raitta and E. Lindahl. 1984. Further lineation of the Cohen syndrome: report on chorioretinal dystrophy, leukopenia and consanguinity. Clinical Genetics 25:1-14.

Nuutila, A. 1968. Neuropsychiatric and Genetic Aspects of the Dystrophia Retinae Pigmentosa-Dysacusis Syndrome. Doctoral Dissertation. Helsinki: University of Helsinki.

O’Brien, E., L.B. Jorde, B. Rönnlöf, J.O. Fellman and A.W. Eriksson. 1988. Inbreeding and genetic disease in Sottunga, Finland. American Journal of Physical Anthropology 75:477-486.

Salonen, R., R. Herva, and R. Norio. 1981. The hydrolethalus syndrome: delineation of a »new» lethal malformation syndrome based on 28 patients. Clinical Genetics 19:321-330. 
Salonen, R., and R. Norio. 1984. The Meckel syndrome in Finland: Epidemiologic and genetic aspects. American Journal of Medical Genetics 18:691-698.

Santavuori, P., H. Somer, K. Sainio, J. Rapola, S. Kruus, T. Nikitin, L. Ketonen and J. Leisti. 1989. Muscle-Eye-Brain Disease (MEB). Brain and Development 11:147-153.

Somer, M. 1993. The PEHO Syndrome: Progressive Encephalopathy with Edema, Hypsarrhythmia, and Optic Atrophy. Doctoral Dissertation. Helsinki: University of Helsinki.

Tahvanainen, E., R. Norio, E. Karila, S. Ranta, J. Weissenbach, P. Sistonen and A. de la Chapelle. 1994. Cohen syndrome gene assigned to the long arm of chromosome 8 by linkage analysis. Nature Genetics 7:201-204.

Takki, K., and O. Simell. 1974. Genetic aspects in gyrate atrophy of the choroid and retina with hyperornithinaemia. British Journal of Ophthalmology 58:907-916.

Tchen, P., E. Bois, J. Feingold, N. Feingold, and J. Kaplan 1977. Inbreeding in recessive diseases. Human Genetics 38:163-167.

Vogel, F. and A.G. Motulsky. 1986. Human Genetics: Problems and Approaches. Berlin: Springer Verlag.

von Wendt, L., A. Hirvasniemi and S. Similä 1979. Nonketotic hyperglycinemia. A genetic study of 13 Finnish families. Clinical Genetics 15:411-417.

WHO (World Health Organization) 1985. Report of a WHO Advisory Group on Hereditary Diseases. Document HMG/WG/85.8a. Geneva: WHO. 